\title{
A Cost Maturity Model for Community Informatics Projects in the Developing World
}

\author{
Ferdie Lochner \\ < flochner@myrealbox.com >
}

\begin{abstract}
Community informatics projects are instituted to achieve global equity in the distribution of information and communication technologies (ICTs) and attendant socioeconomic benefits. Technology disciplines and financial disciplines, specifically management and cost accounting, have no history of goal congruence, and many ICTbased community informatics projects fail, because of a lack of knowledge and insight about their life-cycle costs. This paper introduces a model for systematic measurement and benchmarking of the life-cycle costs of community informatics projects; and invites debate about its bona fides, so that it can be refined and applied to the benefit of communities in the Developing World.
\end{abstract}

\section{Introduction}

This paper formulates a framework for finding answers to problems and questions concerning financial sustainability of community informatics projects in the Developing World. In so doing, it builds upon earlier efforts to draw attention to the intricacies of financial methodologies associated with management of technology in particular. It creates a frame of reference for a discourse about and common understanding of paradigms, concepts, terms and solutions associated with the relationship between technology and financial disciplines, with specific reference to management and cost accounting. By focusing on the cross-disciplinary theme of technology management and its associated financial methodologies, this paper also contributes to an evolving discourse about technology management, training and education in the Management of Technology (MOT) and community informatics academic communities, and seeks to extend that discourse to those in the Developing World who have so far been largely excluded from these discussions.

\section{Background}

It is now commonly understood that valid and accurate technology cost information is vital across all aspects of a business, from product conception, design and production, through pricing policies, supply and delivery, to performance reviews. But managers in technology-based production environments increasingly have to deal with uncertainty as to what accounting methodology to follow. McNair, Mosconi, and Norris (1988, p. xv) observed that the relevance of management and cost accounting in technology rich environments is questioned and that ..."Advanced technologies ... highlight the discrepancies and dysfunction inherent in our management and cost accounting procedures." One of their main observations was that costs became untraceable as a result of the confusion between, respectively, direct and indirect costs, and fixed and variable costs. Macintosh (1994, p.197) finds "....an almost embarrassingly large body of research ... about the darker side of management accounting..." and goes on to describe three conventional categories of critique of management accounting and control systems, i.e. goal congruence, relevance lost and human relations. Peebles and Antolovic (1999) view traditional accounting systems as serving neither operational nor strategic roles at levels below those of major divisions and product lines within an enterprise. These systems can be used to assess the value of inventory and distribute the costs of plant, equipment, and management over major products, but they cannot specify 
the costs required to run a process that produces discrete products and services. Moreover, such accounting systems cannot provide the information through which processes can be re-engineered to reduce cost and increase quality. According to Cooper and Kaplan (2001, p. 96), direct labour, which earlier formed the bulk of cost, now represents only a fraction of corporate costs while expenses associated with production support operations, marketing, distribution, engineering and other overhead functions have increased exponentially. Gupta and Galloway (2003, p.132) confirm the above situation and state that traditional management and cost accounting has been challenged to find methods to help companies better understand and identify business processes and their associated costs.

Though activity-based costing (ABC), life cycle accounting and technology accounting are all seen as having contributed to the emancipation of accounting in technology-rich environments (Glad \& Dilton-Hill, 1993, p. 9), Kaplan \& Anderson (2004, p.131-132) state that numerous managers have abandoned ABC, because of rising costs of implementation, employee frustration, overloading of computing processing capacity, inevitable time delays and, indeed, inaccurate results.

The discussion about technology and how it relates to management and cost accounting certainly makes for vigorous debate in business schools, management and accounting circles and in technologybased industries. Witness the selection of papers on the topic by Robinson (1990), Primrose (1992), Demmy and Talbott (1998), Coate and Frey (1999), Hughes and Paulson Gjerde (2003) and Cooper and Slagmulder (2004). If it is accepted that management and cost accounting are based on general financial fundamentals, how does the MOT community then deal with finance as a general support function, and with management and cost accounting in particular? More to the point and relevant to this paper, how do program and project managers, business incumbents and entrepreneurs in community informatics projects across the Developing World deal with finance and specifically with management and cost accounting, if large and highly evolved organizations have not achieved certainty about the fundamentals?

A literature review of community informatics initiatives associated with the Developing World and the Digital Divide in particular reveals very few references to financial management1, financial accounting, and management and cost accounting practices, as these apply to ICT, its costs of ownership and associated benefits (Adanusa, 2001; Asami, 2001; Boakye, 2001; Truc, 2003, and Tse, 2001). Often these reports make reference to low cost options for technology, or to grants and donations, yet, as in the case of Rajan (2002), referring to a major privately funded initiative in rural India, there is no specific information about the nature of the investment made.

There certainly are a number of commendable efforts at understanding the costs of community informatics projects (Potashnik \& Adkins, 1996; Benjamin, 2001; Blanchard, 2001), but for obvious reasons these efforts do not happen within an agreed-upon standard of accounting for costs, lacking an interaction and scientific discourse about an essential structure such as a common chart of accounts and associated costing benchmarks. Thus, the ultimate impact upon decision-makers is potentially diluted. According to Massachusetts Institute of Technology Professor K. Keniston, as quoted by Rajan (2002), the expectations that ICT could enable even the poorest of developing countries to "...leapfrog traditional problems of development - so as to move them rapidly into the modern Information Age - are largely built on an empirical vacuum..." [author's emphasis]. Keniston furthermore maintains that those involved in developmental projects are not usually in touch with each other, nor do they regularly publish what they are doing. Consequently there is little accumulation of knowledge, with even the most preliminary kind of on-site evaluation lacking, and therefore little possibility of learning from the successes and failures of individual projects, in particular of financially induced failures, as will be argued in this paper. Oberlin (1996, p.21) sums up the situation as: "The financial truths surrounding information technology... have never been particularly clear. The economics of these investments are often steeped in an intellectual haze that can be described as the financial mythology of information technology."

\footnotetext{
${ }^{1}$ Financial management is about analysis of needs, acquisition of funds and effective and efficient deployment of funds. Financial accounting entails bookkeeping and reporting on past financial events. Cost accounting deals with the collection, allocation and control of cost of production; and management and cost accounting entails collecting information for internal financial planning and control for effective financial decision making.
} 


\section{Aim and Objectives}

The aim of this paper is therefore to leverage foundations of theoretical and practical work in order to formulate and test a robust and generic methodology for systematic benchmarking of community informatics projects, in a manner that would meet the most basic developmental needs of the targeted communities. Yet, at the same time, the paper attempts to provide a solution that meets the requirements of developmental agencies for having control and financial sanction over community informatics projects.

The paper introduces a preliminary model to serve as frame of reference for measurement and benchmarking of community informatics projects in the Developing World. The model provides a framework within which answers would be found to four closely related questions associated with the debate presented here, and presently appearing either implicitly or explicitly on the agenda of international developmental agencies. These questions are as follow:

- What tools and programs can be implemented to provide systematic cost measurements of individual community informatics projects in the Developing World?

- How can these measurement results become part of a set of cost benchmarks for community informatics projects?

- How can these benchmarks and the costing status of individual projects be globally communicated as part of project cost management discourse and learning within the appropriate research network?

- What training programs can be implemented by this network, developmental agencies, and other stakeholders, to ensure that financial methodologie, and cost measurements specifically, are synchronized with quickly changing information and communication technologies, inclusive of robust form factors, satellite communications, and liberalizing telecommunication regimes in the Developmental World?

The rest of this paper will endeavor to provide answers to these questions. In doing so, it follows in the footsteps of Potashnik and Adkins (1996) and Benjamin (2001; 2003), drawing attention to the cost of ICT in community informatics projects.

\section{Discussion}

ICT [and for that matter the Digital Divide] is in a race with the "nutrition divide", the "education divide", and the "environmental quality divide". Advocates for technology argue that ICT should prevail because of globalization and the trend for the unit cost of many information and communication technologies to decrease rapidly, compared to costs for those technologies required to overcome the nutrition, education and environmental "divides". Yet, in the words of Ekpo (2001, p.ek-1), there will not be a "...quantum leap into the Age of Information..." if financial management, financial accounting, management and cost accounting, and therefore financial sustainability, of community informatics projects continue to be ignored across the spectrum of development. After all, a thorough knowledge of costs remains essential in order to evaluate and value ICT (Van Maanen \& Berghout, p.167).

There is a lack of financial management and a lack of book-keeping of costs and benefits of ICT infrastructure in community informatics. Indeed, Bridges.org, a prominent NGO analyzing policies about the Digital Divide, often finds a lack of management capacity, entrepreneurship, affordability, marketing and financial sustainability in its assessments of a large selection of on-the-ground initiatives to bridge this divide (Bridges.org, 2001). Clearly, the problem cannot be one of lack of will or ability to reach out; not if so many institutions and individuals have participated in these developmental efforts, supported by a wide range of funding institutions, with often significant budgets. In reality, if Oberlin (1996), Potashnik and Adkins (1996) and others are to be taken seriously, the problem is the lack of management capacity and a lack of common understanding of general financial methodologies. 
Roberto Verzola (2002) asserts that a distinguishing feature of ICT is that while the cost of moving or copying information goods is approaching zero, the initial costs involved for creating new information, or infrastructure for moving and manipulating information goods, remain relatively high. As an example of the above, Verzola submits the now familiar technology cost equation which sees a high setup cost for ICT infrastructure such as a telecommunications network followed by a nominally marginal cost of "information transfer". This, according to Verzola, makes ICT often more accessible to those who can afford the high start-up cost than to the poor. However, it is time for developmental agencies, decisionmakers and project managers in Community Informatics to be aware of conventional wisdom in technology accounting: that start-up costs represents only a fraction of the annual Total Cost of Ownership [TCO] of ICT (Tissue, 1997; Gartner, 2002); and that, when combined, the annual total costs of ownership of ICT form the life-cycle cost of ICT, or the total cost of ownership over the useful life of ICT. Within the specific context of community informatics, the same view is also confirmed by Adam (2002) and Benjamin (2003). Therefore, to not know, understand and manage the full life-cycle TCO of ICT in community informatics programs invites failure, since at best procurement cost represent only one fifth of the annual TCO, and at worst only one twentieth, depending on the architecture, standards, form factor, functionality and scope of the particular ICT environment; the obvious implication is that the rest of the costs go unnoticed and unmanaged.

The argument to be constructed here is not intended to take away a general focus on the affordability, or lack thereof, of ICT to the poor, a focus strongly supported inter alia by the UN Secretary-General Kofi Annan (Wall, 2000). But in strengthening the effort of making ICT more affordable, indeed more sustainable and more accessible, it undoubtedly makes sense to point to the need for generation, management and communication of valid life-cycle cost information about ICT solutions, and then to identify the affordability thereof. Projects need proper business cases, with pricing strategies informed by annual cost of ownership measurement, and benchmarking, fed into simplified budgets so that financial feasibility and proper management get built into project plans.

\section{Total Cost of Ownership [TCO] models}

TCO is a vital concept in technology cost management, specifically in ICT cost management, and for the purpose of this paper represents a desirable end state of cost maturity. It is a generic management and cost accounting concept, normally measured and managed as an annual variable. Technically it is derived from the more commonly found life cycle 2 view of costs (Ansari et al, 1997). Many ICT vendors, most notably Microsoft, HP, IBM, CA, Siemens and Unisys, have used the concept in one form or another to distinguish products based on costs; indeed, some have even developed the TCO concept into practical decision-making models, based on work done by ICT research firms such as Gartner and the now defunct Meta Group3. Yet management of TCO and indeed of life-cycle TCO of ICT remains a common challenge across the world and across all sectors of industry. Relatively few organizations, outside of large corporations, have had the required financial and human resources to implement it as a so-called best practice.

Bill Kirwin contributed to the creation of the TCO for computing methodology in 1987 (Kirwin, 2004) and has since helped Gartner in popularizing it by creating a database of TCO benchmarks, consisting of cost measurements of different ICT domains of organizations across the globe. Gartner today defines TCO as a comprehensive set of methodologies, models and tools to help organizations better measure, manage, and reduce costs and improve overall value of IT investments over the useful life of ICT assets (Gartner, 2002, p. 4). Van Maanen and Berghout (2002, p.167-168) use this as a foundation for a further distinction

\footnotetext{
${ }^{2}$ The life cycle view of cost arranges costs according to the time they are incurred. Some costs appear early in the product life cycle (R\&D) and some are incurred many years later (disposal \& environmental costs). This time-based view allows organizations to not only focus on today's costs but also on future costs committed by today's decisions. It also encourages a long-term view of costs that considers both a producer's as well as a customer's life cycle costs.

${ }^{3}$ Meta was taken over by Gartner in the first semester of 2005.
} 
between the TCO of an information system and the TCO of an organization. Whereas the former is “... all the costs associated with owning and using the information system throughout its life cycle", the latter is ..."all the costs associated with owning and using IT by the organization over a certain period of time."

Pursued to its logical end, TCO helps organizations to understand the cost of procuring, owning and using ICT over time; to create, implement and manage a financial plan for ICT budgeting, operations and investment planning; and to understand the relationship between ICT investments and business value. As a holistic financial concept, its value as a management objective is beyond doubt. So much so that a Gartner TCO maturity model has evolved from the original concept. The TCO maturity model describes the availability and integrity of cost data, the manner of collecting and maintaining the data, and the degree of assistance needed to calculate TCO with a reasonable level of validity. The model has five levels. At the lowest level, there is little or no awareness of the need for or benefits of a management program that includes a TCO approach. At that level, TCO efforts involve searching for data or making educated guesses. At higher levels, the TCO processes have matured to the point where organizations routinely and independently conduct TCO assessments. They obtain highly reliable metrics, and incorporate them into budgeting and planning, communication with stakeholders, and comparisons to peer groups.

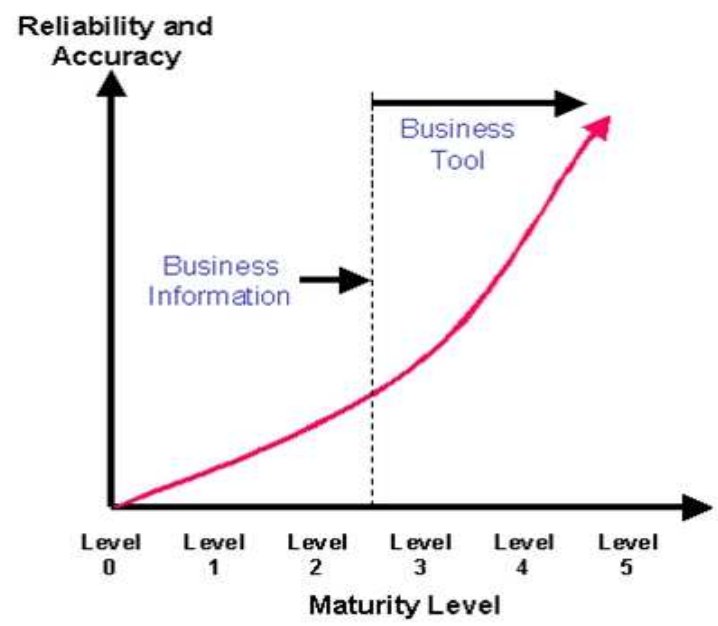

Figure 1: The Gartner TCO Maturity Model (Source: Gartner Research, 2003)

The specific value of the TCO maturity model in the context of this paper is threefold. Firstly, it confirms the continued refinement of the TCO concept in a world where technology and its peculiar cost configurations are highly dynamic; secondly, it recognizes that different communities have different levels of readiness for understanding and managing ICT costs and associated administrative imperatives; and thirdly, it has been developed for the educational and training sector and presents an almost intuitive frame of reference for future measurement and benchmarking work by developmental agencies overseeing community informatics projects. Altogether, the concept of total Cost of Ownership presents a logical foundation for a model that would support systematic cost measurement and benchmarking of community informatics projects in the Developing World.

A preliminary model for measurement and benchmarking of community informatics projects in the Developing World

If all the normal cost considerations involved in owning and managing a community informatics project were to be combined in one view, it would form a cost cascade (Figure 2) from a very basic understanding of what cost is, towards a state of complete cost efficiency, defined as using the minimum amount of resources to do the assigned job (Chorafas, 2004, p. 11). 
- Are costs transparent?

- What are costs for processes \& activities?

- What are overhead costs?

- What costs are fixed and what are variable?

- How do costs compare to prices?

- How often are costs measured?

- Are costs in line with budget?

- How do costs compare in different domains of production?

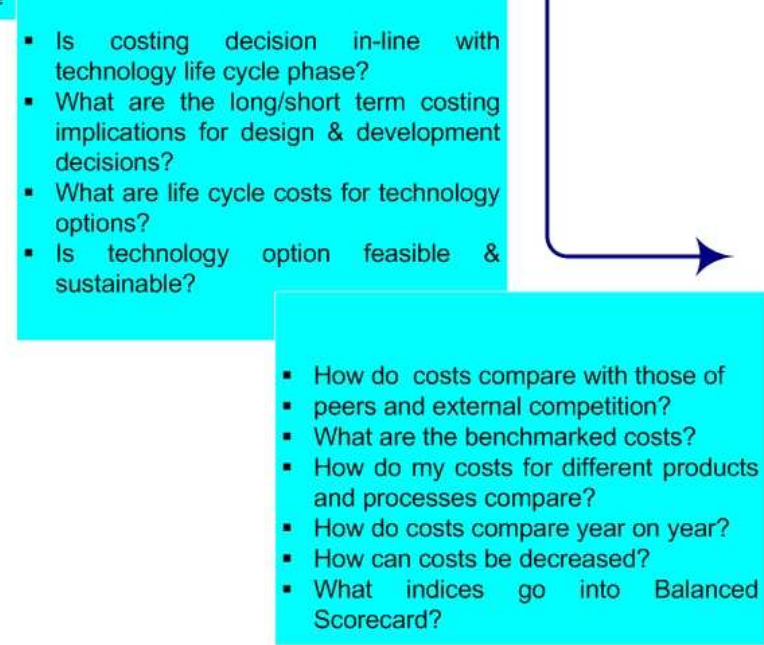

Figure 2: The Technology Cost Management cascade

Flow towards cost

efficiencies

Both the Gartner TCO Maturity model and the Technology Cost Management cascade make the assumption that building blocks are in place to progress from a generally inefficient stage to cost maturity. The Cost Maturity model for community informatics projects in the Developing World combines elements from both these approaches in a practical manner and simplifies the concepts involved. It assumes that very few communities in the Developing World have the required skills and training to fully understand the type of questions posed in the Technology Cost Management cascade, nor the cost measurement and analysis skills implied by the later stages of the TCO Maturity model. The proposed model also assumes a total absence of standardized charts of accounts and existing measurement benchmarks, as would be available for the TCO Maturity model. Finally it simply projects itself as a free tool that would be available to communities in need, with access to knowledge and associated benchmarks available to all community informatics projects.

The Cost Maturity model (Figure 3) basically consists of a benchmarking stream augmented by any of a number of interventions, which can be evoked at any phase in the selection, measurement and benchmarking process of individual community informatics projects, or groups of projects. It includes at the same time a maturity continuum of financial practices for understanding costs and benefits of ownership; and presents a modular and flexible training framework reflecting rapidly evolving ICT technologies. Beyond serving as a frame of reference, the proposed utility value of the Cost Maturity model lies in the fact that it recognizes the diversity of circumstances and inherent constraints found in the endeavour to manage technology and technology cost and benefit accounting in the Developing World; and in reaction to these conditions presents a flexible route towards cost maturity. It must be clearly stated, though, that its flexibility lies in the fact that community informatics projects that have some of the required building blocks in place can come on board, and not in a laissez faire approach that accommodates projects without supporting structures towards cost maturity.

The model does, however, also reflect a number of novelties, which need to be debated, tested, and refined, including the following:

- It assumes different levels of sophistication for the incumbent community informatics project manager, custodian or proprietor. 
- It makes provision for generic as well as more specialized community informatics projects.

- It provides for a robust index of cost maturity.

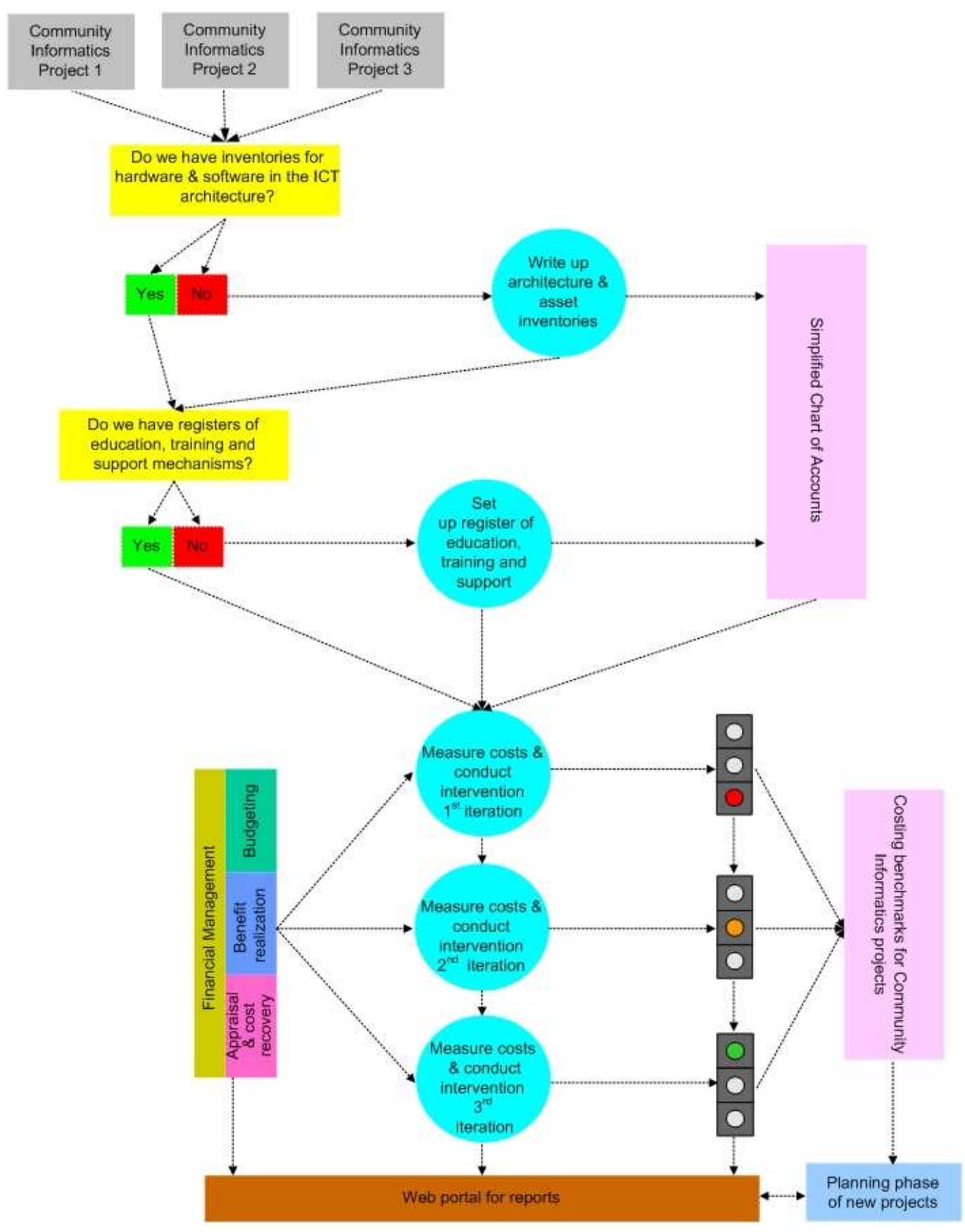

Figure 3: The Cost Maturity Model for community informatics projects

- The model promotes simplified and appropriate training content in the measurement and benchmarking process.

- The model has soft lines, and reflects an iterative process, so that measurement, analysis, benchmarking and training can be repeated as often as is required and as resources become available to do so. Yet it recognizes resource constraints and aims at financial and cost 
independence of community informatics projects along the shortest route possible. A community informatics project having achieved cost maturity would ultimately be able to produce a full Cost of Ownership data set, with its associated costs and benefits (in the form of income and tangible assets only, with the notion of intangibles left out of the equation).

- It assumes a simplified and even intuitive General Ledger, which would at its most basic level simply have single entry accounting, if circumstances so prescribe.

- It provides for a simplified Chart of Accounts, which would have generic cost categories and which could be exploded in accordance with the sophistication, training and complexity of ICT equipment, as well as in accordance with the level of detail required.

- It provides for two methods of implementation, i.e., an inductive method where individual projects receive intervention sequentially; or a deductive method where a number of community informatics projects receive intervention at the same time across a specific region, albeit in accordance with its respective sets of circumstances.

Altogether the model presents an opportunity to prepare, in a structured and systematic manner, for measurement of the cost management status of individual community informatics projects against a set of appropriate benchmarks. It also accounts for subsequent re-measurement of these projects, and ultimately for the construction of an 'intervention dashboard' reflecting cost status and control. It presents itself as a developmental tool to be activated within the conceptual realms of management and cost accounting, but also makes itself available as a cross-disciplinary concept relevant to training for technologists, entrepreneurs and others involved with management or financial custodianship of community informatics projects in the Developing World.

However, it is only a preliminary model requiring follow-up work, most notably in the areas of measurement and benchmarking of community informatics projects having the required profiles and indeed the business need to be measured. Keeping at a practical and very basic level, the model also proposes discarding the conventional double entry bookkeeping system at lower levels of sophistication in favor of a single entry system, i.e., a simple income and expense set of entries4. It tacitly poses the question of whether financial methodologies in these circumstances should be automated, and indeed whether a tool fundamental to accurate TCO recording and processing, i.e., the omnipresent spreadsheet program, should be part of the equation. The model also reflects the real constraints and general lack of understanding surrounding benefit calculation, in particular leaving to the wayside intangible benefits. Finally, it contemplates the need for a database of developmental-friendly financial benchmarks, made available through a community informatics web portal, so that newly planned projects can leverage the knowledge gained by existing projects, and can, pre- and post-implementation, be evaluated against their peers elsewhere in the world.

In reply to the stated problem, the Cost Maturity model presents a generic, flexible and modular framework, and proposes interventions, for measurement and benchmarking of ICT developmental projects. Ignoring the proposed model and its plea for debate, testing and refinement, leaves countless community informatics projects in the cold and leads inevitably towards project failure. Ignoring it also means that the discourse about management and cost accounting of technology is an exclusive endeavor not accessible to those mostly in need of its enlightenment. This discussion must therefore conclude with an invitation to have community informatics projects measured and benchmarked, so that a foundation of understanding, so clearly required in the Developing World, can be built and grown for the benefit of all present and indeed future developmental endeavors involving ICT.

\section{Conclusion}

${ }^{4}$ Double entry bookkeeping brings an extra layer of control into the bookkeeping process and guarantees accurate profit and loss accounting in complex organizations. Single entry systems do not track asset and liability accounts; they facilitate calculation of income, but not of financial position, and may allow errors to go undetected. 
Management of Technology is a young, evolving and multi-disciplinary science. Part of its interest is in general financial management of technology, but specifically in management and cost accounting of technology - an exact field of practical and scientific endeavor, with equally exact methodologies. To those who have the means, it is a transparent and stimulating academic process, its content disseminated across the globe. But evidence has been provided here that the Developing World often has to forego the luxury of scientific information and learning as far as management and cost accounting of ICTs in community informatics projects are concerned. Given its comprehensive developmental imperatives, the Developing World cannot afford to continue along the same route; and this paper therefore has proposed a model for measurement and benchmarking of ICT costs, and where appropriate, benefits of community informatics projects. In practice it merely intends to create a framework for facts to be gathered about the cost feasibility and sustainability of community informatics projects, and for management skills to be created to deal with these facts. But at an academic level it looks to extend multi-disciplinary Management of Technology approaches to the wider community of technology practitioners and so contribute to the success of developmental efforts. Based on the evidence in this paper, there are indeed practical solutions to be had to the problems of financial feasibility and sustainability of community informatics projects in the Developing World, and debate about these solutions is encouraged.

\section{References}

Adam, L. 2002. Africa and the Digital Divide: Status, Issues, Initiatives. Available at http://www.oosa.unvienna.org/SAP/stdm/2002_africa/presentations/session06/speaker02.pdf

Adanusa, G.K. 2001. Improving Intra-Africa Connectivity. Policy \& Development: Strategic Initiatives \& Solutions - Strategies to bridge the digital divide: ITU Telecom Africa 2001. Johannesburg. ITU.

Ansari, S.L., Bell, J.E. 1997. Target Costing: The Next Frontier in Strategic Cost Management. Chicago. Irwin.

Asami, T. 2001. Island Community Wireless Networks. Infrastructure \& Applications: Providing Access for Underserved Communities: ITU Telecom Africa 2001. Johannesburg. ITU.

Benjamin, P. 2001. Experience from Community ICT projects. Policy \& Development: Accessibility \& Opportunities: ITU Telecom Africa 2001. Johannesburg. ITU.

Benjamin, P. 2003. The Universal Service Agency's Telecenter Programme: 1998- 2000. Surveys, Analyses, Modelling and Mapping Research Programme, Occasional Paper 2, Cape Town. Human Sciences Research Council.

Blanchard, J. 2001. Technology: Threat or Opportunity. Youth Forum. ITU Telecom Africa 2001. Johannesburg. ITU.

Boakye, K.A. 2001. The Internet: Building the First Mile. Infrastructure \& Applications: Broadband Access in the Last Mile and the Last Metre: ITU Telecom Africa 2001. Johannesburg. ITU.

Bridges.org, 2001. Spanning the Digital Divide: Understanding and Tackling the Issues. A report by Bridges.org. Available at http://www.bridges.org/spanning/index.html

Coate, C.J., Frey, K.J. 1999. Integrating ABC, TOC, and financial reporting. Journal of Cost Management, July/August, 22-27.

Chorafas, D.N. 2004. Rating Management's Effectiveness: With Case Studies in Telecomunnications. Hampshire: Palgrave MaCmillan.

Cooper, R., Slagmulder, R. 2004. Achieving Full-Cycle Cost Management. MIT Sloan Management Review, 46(1), 45-52.

Demmy, S., Talbott, J. 1998. Improve internal reporting with ABC and TOC. Management and cost accounting, November, 18-24. 
Ekpo, E.O. 2001. Africa in the Age of Information: Cheetah - Pole Vaulting or Merely Tiptoeing? Policy \& Development: Strategic Initiatives \& Solutions - Strategies to bridge the digital divide: ITU Telecom Africa 2001. Johannesburg. ITU.

Gartner, 2002. Decision Engine for Cost Management. TCO Manual. Maitland. Gartner Inc.

Gartner Research, 2003. TCO in Education The Time Is Right. Available at http://www4.gartner.com.

Glad, E., Dilton-Hill, K. 1993. Cost Management in World Class Companies. Accountancy SA, May, 69.

Gupta, M., Galloway, K. 2003. Activity-based costing/management and its implications for operations management. Technovation 23, 131-138.

Hughes, S.B., Paulson Gjerde, K.A. 2003. Do different cost systems make a difference? Management and cost accounting Quarterly. Available at http://www.imanet.org/ima/

Kaplan, R.S., Anderson, S.R. 2004. Time-Driven Activity-Based Costing. Harvard Business Review, November, 131-138.

Kirwin, B., Vice-President, Gartner, 2004. Statement to author, 19 March. Cape Town.

McNair, C.J., Mosconi, W., Norris, T. 1988. Meeting the Technology Challenge: Cost Accounting in a JIT Environment. Montvale. National Association of Accountants.

Oberlin, J.L. 1996. The Financial Mythology of Information Technology: The New Economy. Cause/Effect, Spring 1996, 21-29.

Peebles, C.S., Antolovic, L. 1999. Cost (and Quality of Value) of Information Technology Support in Large Research Universities. Educom Review, 34(5). Available at http://www.educause.edu/LibraryDetailPage/666?ID=ERM9955

Phaal, R., Paterson, C.J., Probert, D.R. 1998. Technology management in manufacturig business: process and practical assessment. Technovation, 18(8/9), 541-553.

Potashnik, M., Adkins, D. 1996. Cost Analysis of Information Technology Projects in Education: Experiences from Developing Countries. Education and Technology Series, 1(3), 1-21.

Primrose, P.L. 1992. Is anything really wrong with cost management? Journal of Cost Management, Spring, 48-57.

Rajan, M.A.S. 2002. Narrowing the digital divide in rural areas. The Hindo Business Line Internet Edition. 8 February. Available at http://www.blonnet.com/2002/02/08/stories/2002020800480900.htm

Robinson, M.A. 1990. Contribution margin analysis: No longer relevant/strategic cost management: The new paradigm. Journal of Management and cost accounting Research, 2, 1-32.

Tissue, B.M. 1997. The Cost of Incorporating Information Technology in Education. Summer On-Line Conference on Chemical Education. Available at http://www.chem.vt.edu/archive/chemconf97/paper04.html

Truc, M.L. 2003 (chair). Panel Discussion on Globalization and WTO: ICT , Trade and Competitiveness. Asian Forum on Information and Communication Technology Policies and e-Strategies. Kuala Lumpur.

Tse, M. 2001. VOIP in Africa. Corporate Africa, 22(1), 43-45.

Van Maanen, H., Berghout, E. 2002. Cost management of IT beyond cost of ownership models: a state of the art overview of the Dutch financial services industry. Evaluation and Program Planning, 25, 167-173.

Van Wyk, R.J. 2004. Report to the Education Committee: International Association for Management of Technology (IAMOT). Available at http://www.iamot.org/ 
Verzola, R. 2002. Low Cost Strategies for Developing Countries. Available at http://mail.sarai.net/pipermail/solaris/2002-April/001137.html

Wall, T. 2000. Ecosoc 2000 - High Level Segment - Information Technology for the World. Available at http://www.un.org/esa/coordination/ecosoc/itforum/expert.htm 